\title{
Diversity and temporal dynamics of Southern California coastal marine cyanophage isolates
}

\author{
Jessica L. Clasen ${ }^{1,3, * *}$, China A. Hanson ${ }^{1,4, * * *}$, Yazeed Ibrahim ${ }^{1}$, Claudia Weihe $^{1}$, \\ Marcia F. Marston ${ }^{2}$, Jennifer B. H. Martiny ${ }^{1}$ \\ ${ }^{1}$ Department of Ecology and Evolutionary Biology, University of California, Irvine, California 92627, USA \\ ${ }^{2}$ Department of Biology and Marine Biology, Roger Williams University, Bristol, Rhode Island 02809, USA \\ ${ }^{3}$ Present address: Department of Zoology, University of British Columbia, Vancouver, British Columbia V6T 1Z4, Canada \\ ${ }^{4}$ Present address: School of Civil Engineering and Geosciences, Newcastle University, Newcastle upon Tyne NE1 7RU, UK
}

\begin{abstract}
Marine ecosystems contain an immense diversity of phages, many of which infect the cyanobacteria responsible for a portion of oceanic primary productivity. To add to the growing body of research on the dynamics and diversity of these cyanophages, we measured cyanophage abundance, diversity, and community composition monthly for 15 mo at 3 coastal locations in Southern California, USA. We characterized over 900 individual cyanophages, isolated on Synechococcus sp. WH7803, by amplifying and sequencing 2 different genes from each isolate: $g 20$ (the portal protein gene) and psbA (a host-derived gene involved in photosynthesis). The taxonomic composition and diversity of isolated cyanophages were highly variable over time, with little variation across the 3 locations. Particular taxa dominated the community at distinct times of year, with more rapid turnover of dominant types and higher overall abundance and diversity during spring and summer. These temporal patterns as well as taxonomic designations were highly congruent for both genes, based on operational taxonomic units (OTUs) defined at $99 \%$ nucleotide similarity, despite a greater level of amino acid conservation within psbA as compared to g20. Overall, this suggests that either gene can serve as a useful marker for cyanophage diversity. However, we detected 1 myovirus taxon (representing about $2.5 \%$ of the isolates) of uncertain phylogenetic affiliation that was negative for $p s b A$ amplification. Further sampling is necessary to assess whether these temporal dynamics in cyanophage composition, diversity, and abundance are seasonally recurring.
\end{abstract}

KEY WORDS: Cyanophage $\cdot g 20 \cdot p s b A \cdot$ Myovirus $\cdot$ Synechococcus $\cdot$ Temporal $\cdot$ Diversity

\section{INTRODUCTION}

Viruses are the most abundant and diverse biological entities in the Earth's oceans (Suttle 2007). Recent work suggests that thousands of viral genotypes coexist in several hundred liters of seawater (Breitbart \& Rohwer 2005) and that hundreds of thousands of marine viral 'species' persist globally, the majority of which infect microorganisms (Angly et al. 2006). Further, much of the viral genetic diversity observed in recent metagenomic libraries is entirely novel, with 65 to $95 \%$ of sequences unlike any others in genomic databases (Breitbart et al. 2004, Angly et al. 2006, Culley et al. 2006) .

Some understanding, however, of marine viral diversity has been garnered from studies of marine cyanophages - the viruses that infect the cyanobacteria genus Synechococcus. Synechococcus spp. are abundant in coastal marine surface waters, and are thought to be responsible for up to $30 \%$ of marine 
primary productivity (Waterbury et al. 1986, Partensky et al. 1999). Cyanophages are also abundant in coastal waters, with estimates of up to $10^{5}$ cyanophage particles $\mathrm{ml}^{-1}$ (Waterbury \& Valois 1993, Wilson et al. 1993, Suttle \& Chan 1994). At any one time, 1 to $5 \%$ of cyanobacterial cells in the ocean are estimated to be infected by phages (Proctor \& Fuhrman 1990, Suttle \& Chan 1994, Garza \& Suttle 1998). Through infection and lysis of host cells, cyanophages influence cyanobacteria turnover rates and marine nutrient cycling (Suttle et al. 1990, Thingstad 1997, Fuhrman 1999, Wilhelm \& Suttle 1999), and they may also have an effect on host abundance and diversity (Thingstad 2000, Middelboe et al. 2001, Schwalbach et al. 2004, Weinbauer \& Rassoulzadegan 2004).

Studies over the last 2 decades have demonstrated that marine cyanophage diversity is both spatially and temporally dynamic. Cyanophage diversity and community composition often varies by depth, having highest diversity in the water column at depths corresponding to the deep chlorophyll a maximum and/or maximum abundances of Synechococcus or Prochlorococcus cells (Wilson et al. 1999, Zhong et al. 2002, Frederickson et al. 2003). Patterns over horizontal space are less consistent, however. Some studies suggest that cyanophage composition exhibits little horizontal spatial variation, given that nearly identical cyanophage gene sequences have been identified in surface marine samples collected from distant locations (Zhong et al. 2002, Breitbart et al. 2004, Short \& Suttle 2005, Chénard \& Suttle 2008, Huang et al. 2010). Other studies, however, have identified compositional variation among locations. In these cases, the patterns appear to be related to salinity, whereby freshwaters harbor cyanophage taxa not found in marine habitats (Short \& Suttle 2005, Chénard \& Suttle 2008, Sullivan et al. 2008, Wang et al. 2010). Indeed, we know of only 1 study that found evidence for genetically distinct cyanophage communities across relatively small $(<100 \mathrm{~km})$ scales within a marine system (Frederickson et al. 2003).

In contrast, temporal variation in marine cyanophage communities tends to be a more consistent observation. For example, cyanophage abundance and diversity varies seasonally, and is typically higher in spring or summer months (Marston \& Sallee 2003, Dorigo et al. 2004, Wang \& Chen 2004, Mühling et al. 2005, Sandaa \& Larsen 2006, Chen et al. 2009, Chow \& Fuhrman 2012, Parsons et al. 2012). Cyanophage composition is also temporally variable, particularly within years. Such intraannual variation in composition has been observed on the Atlantic coast of the United States (Marston \& Sallee 2003, Wang \& Chen 2004), along the coast of Norway (Sandaa \& Larsen 2006), and in the Red Sea (Mühling et al. 2005). However, direct comparison of variation in time across multiple locations is necessary to understand whether this temporal variation is predictable for cyanophage communities across diverse oceanic regions.

The present study examined the diversity and community composition of marine cyanophages over both time and space. An isolation-based approach was used to characterize cyanophages that infect the marine cyanobacterium Synechococcus sp. strain WH7803. Although this methodology greatly undersamples the total cyanophage community, it provides several advantages that complement culture-independent studies. First, because the viruses replicate on the same host strain, they likely share some of the same hosts in the natural community. Thus, the approach targets a viable, and potentially ecologically meaningful, subset of the cyanophage diversity present. Second, this reduced subset of all cyanophages provides a tractable amount of viral diversity for making robust statistical comparisons across samples. Last, an isolation-based approach allows each virus to be studied individually, and multiple regions of the genome can be compared across individuals (Marston \& Amrich 2009).

For the present study, we isolated and purified more than 900 cyanophages from 3 coastal locations in Southern California, USA, over 15 mo. We genetically characterized each isolate by PCR-amplifying and sequencing 2 cyanophage marker genes that differ in evolutionary history, $g 20$ and $p s b A$. Both genes are present in the genomes of most cyanophages of the Myoviridae family (cyanomyoviruses) (Sullivan et al. 2006, 2008), which constitute the majority of cyanophages both isolated from seawater (Waterbury \& Valois 1993, Wilson et al. 1993, Marston \& Sallee 2003) and detected in marine metagenomic libraries (Breitbart et al. 2002, Williamson et al. 2008). The $g 20$ gene, involved in capsid assembly, is conserved within the Myoviridae and thus commonly used as a phylogenetic marker (Fuller et al. 1998). $p s b A$ is a functionally conserved host-derived gene encoding the D1 protein of photosystem II (Mann 2003, Lindell et al. 2004). With these data, we asked 2 questions: (1) Does cyanophage diversity and composition vary temporally or spatially across 3 coastal sampling sites located in Southern California? (2) How does spatial and temporal variation in diversity and composition compare across the 2 genes? 


\section{MATERIALS AND METHODS}

\section{Sampling}

Three replicate surface seawater samples $(60 \mathrm{ml}$ to 1 l) were collected once per month from January 2008 to March 2009 from the surf zone of 3 Southern California coastal sites: Seal Beach $\left(\mathrm{SB}_{i} 33^{\circ} 44^{\prime} \mathrm{N}\right.$, $118^{\circ} 6^{\prime} \mathrm{W}$ ), Balboa Island (BI; $33^{\circ} 36^{\prime} \mathrm{N}, 117^{\circ} 53^{\prime} \mathrm{W}$ ), and Crystal Cove State Beach $\left(\mathrm{CC}_{i} 33^{\circ} 34^{\prime} \mathrm{N}, 117^{\circ}\right.$ $\left.50^{\prime} \mathrm{W}\right)$. Approximate pairwise distances between sites are as follows: CC to BI: $8 \mathrm{~km}$; CC to $\mathrm{SB}: 32 \mathrm{~km}$; BI to SB: $23 \mathrm{~km}$. For each sampling event, samples were collected between 07:00 and 11:00 $\mathrm{h}$ at each site, transported in the dark, and processed within $3 \mathrm{~h}$ of collection. Weekly average sea surface temperature measurements at $2 \mathrm{~m}$ depth were recorded by the Southern California Coastal Ocean Observing System (SCCOOS) at the Newport Pier ( $33^{\circ} 35.94^{\prime} \mathrm{N}$, $\left.117^{\circ} 54.00^{\prime} \mathrm{W}\right), 2 \mathrm{~km}$ northwest of the BI site, using a mounted SEACAT instrument.

\section{Estimation of cyanophage abundance}

The abundance of cyanophages capable of infecting Synechococcus sp. WH7803 at the BI site was estimated using a most probable number (MPN) assay, modified from Marston \& Sallee (2003). Briefly, a subsample $(60 \mathrm{ml})$ of each replicate seawater sample was centrifuged to remove large particles and bacteria, and the supernatant was serially diluted with sterile natural seawater media (SN media, Waterbury et al. 1986). A $100 \mu \mathrm{l}$ aliquot of this diluted seawater was added to $100 \mu \mathrm{l}$ of exponentially growing Synechococcus sp. WH7803 in each well of 48well microtiter plates (except control wells which received no seawater). After a 30 to $60 \mathrm{~min}$ incubation at room temperature, $500 \mu \mathrm{l}$ of sterile SN media was added to each well. Plates were then incubated for $2 \mathrm{wk}$ at $25^{\circ} \mathrm{C}$ under a $14 \mathrm{~h}$ light: $10 \mathrm{~h}$ dark cycle at $19 \mu \mathrm{E} \mathrm{m}^{-2} \mathrm{~s}^{-1}$ light intensity. After $14 \mathrm{~d}$, the plates were visually monitored for lysis (wells with less visible pigmentation than control host-only wells), and the total number of lysed wells was recorded. Estimates of the concentration of infectious cyanophages were determined using the MPN Calculator Build6 freeware (Curiale 2004플. While we set up similar plates using diluted samples (referred to as 'dilution plates') from each of the other 2 sites each month (Crystal Cove and Seal Beach), we did not include

$\underline{1}_{\text {Www.i2workout.com/mcuriale/mpn/index.html }}$ replicate plates for these sites during January to October 2008. For this reason, MPN abundances were estimable for the BI site only for the majority of the sampling period; therefore, only this site is included in the MPN abundance data presented in Fig. 3A.

\section{Cyanophage isolation}

Cyanophages were enriched using the same MPN plates (or dilution plates for Crystal Cove and Seal Bach) as described above. After plates had been incubated for $3 \mathrm{wk}$, the liquid in lysed wells (lysate) was collected. To minimize the selection of only fastgrowing cyanophages, we collected lysates from plates with less than $50 \%$ of the wells cleared. We aimed to collect 50 lysates from each site, per month, although this was not always possible due to low MPN titers during some months. The lysates were stored in cryogenic vials in the dark at $4^{\circ} \mathrm{C}$ for up to 12 mo prior to purification by plaque assay following Marston \& Sallee (2003). To purify, each cyanophage lysate was serially diluted and combined with concentrated Synechococcus sp. WH7803 culture and warm $\left(37^{\circ} \mathrm{C}\right)$ sterile SN media (Waterbury et al. 1986) containing $0.3 \%$ washed agar (Waterbury \& Willey 1988). This mixture was poured over a $0.6 \%$ agar SN plate and incubated at $25^{\circ} \mathrm{C}$ under a $14 \mathrm{~h}$ light: $10 \mathrm{~h}$ dark cycle. Plates containing host cells but no viral lysate were also included as controls. Plaques were never observed on these control plates. Upon the appearance of plaques (typically 4 to $7 \mathrm{~d}$ ), a single plaque was picked from each plate and regrown on a WH7803 liquid culture in microtiter plates. Each plaque-purified lysate was then treated with chloroform (final volume $10 \%)$ and centrifuged $(2000 \times g$ for $10 \mathrm{~min}$ ) to remove remaining host cells and debris. The supernatant containing a purified cyanophage was transferred to a cryogenic vial for storage in the dark at $4^{\circ} \mathrm{C}$.

\section{Genetic analysis}

Each plaque-purified isolate was used directly as template DNA in PCR reactions targeted at 2 separate genes, $g 20$ and $p s b A$, both of which are found in the genomes of most, if not all, cyanophages in the Myoviridae family (Sullivan et al. 2006, 2008, 2010). The g20 gene was amplified using the primers CPS1.1F (5'-GTA GWA TWT TYT AYA TTG AYG TWG G-3') and CPS8.1R (5'-ART AYT TDC CDA YRW AWG 
GWT C-3') (Sullivan et al. 2008). Each PCR reaction $(30 \mu \mathrm{l})$ contained $1 \times$ PCR buffer, $1.5 \mathrm{mM} \mathrm{MgCl}_{2}, 0.2$ $\mu \mathrm{M}$ of each primer, $250 \mu \mathrm{M}$ dNTPs, 1 U 5 Prime HotMaster Taq polymerase (5 Prime), and $1.5 \mu \mathrm{l}$ of plaque-purified cyanophage isolate as template. The reaction parameters were a denaturing step at $94^{\circ} \mathrm{C}$ for $3 \mathrm{~min}$ and then 34 cycles of $94^{\circ} \mathrm{C}$ for $45 \mathrm{~s}$, annealing at $48.2^{\circ} \mathrm{C}$ for $45 \mathrm{~s}$ and extension at $72^{\circ} \mathrm{C}$ for $1 \mathrm{~min}$, followed by a final extension step at $72^{\circ} \mathrm{C}$ for 4 min. The $p s b A$ gene was amplified using the primers psbA-93F (5'-TAY CCN ATY TGG GAA GC-3') and psbA-341R (5'-TCR AGD GGG AAR TTR TG-3') (Wang \& Chen 2008). Each $30 \mu$ reaction contained $1 \times$ PCR buffer, $1.5 \mathrm{mM} \mathrm{MgCl}_{2}, 250 \mu \mathrm{M}$ dNTPs, $0.5 \mu \mathrm{M}$ of each primer, $1 \mathrm{U}$ Platinum Taq DNA polymerase (Invitrogen), and $1.5 \mu$ l of plaque-purified cyanophage isolate as template. The reaction parameters were $94^{\circ} \mathrm{C}$ for $3 \mathrm{~min}$, followed by 36 cycles of $94^{\circ} \mathrm{C}$ for $1 \mathrm{~min}$, $55^{\circ} \mathrm{C}$ for $30 \mathrm{~s}$ and $72^{\circ} \mathrm{C}$ for $1 \mathrm{~min}$, and then a final extension step at $72^{\circ} \mathrm{C}$ for $10 \mathrm{~min}$. The $g 20(\sim 540 \mathrm{bp})$ and psbA ( 600 bp) products were sent to Agencourt Biosciences for Sanger sequencing using the $g 20$ forward primer and the $p s b A$ reverse primer. Note that the number of quality sequences obtained varied both by month and by locus ( $g 20$ : ranging from 10 sequences in January 2008 and April 2008 to 130 in September 2008; psbA: ranging from 6 in May 2008 to 101 in September 2008).

The partial gene sequences were edited and aligned using MUSCLE in Geneious 4.6.2. After trimming and editing, the resulting sequence fragments were $\sim 510$ and $\sim 575$ bp in length for $g 20$ and $p s b A$, respectively. DNA distance matrixes were constructed in PHYLIP v.3.68 (Felsentein 1993) using the F84 distance model. Operational taxonomic units (OTUs) based upon a 99\% nucleotide sequence similarity threshold were designated using the nearest-neighbor cluster algorithm in mothur v.1.14.0 (Schloss et al. 2009). This cutoff threshold was chosen in order to be consistent with other work on cyanophage isolates (e.g. Marston \& Amrich 2009, Marston et al. 2012). One representative sequence for each OTU was selected using the get.otureps function in mothur and used to build Neighbor-Joining phylogenetic trees in Mega5 for Mac (Tamura et al. 2007) with bootstrap support calculated from 10000 replications. OTU representatives were also used for GenBank BLAST searches using blastn and blastx batch search functions, as well as for MEGA BLAST searches of the Global Ocean Survey (GOS) metagenomic database through the CAMERA portal (Sun et al. 2011). The partial $g 20$ and psbA gene sequences of OTU representatives have been deposited in GenBank as
JX218109 to JX218152, (see also Tables S1 to S3 in the Supplement at www.int-res.com/articles/suppl/ a069p017_supp.pdf).

\section{Diversity metrics and statistical analyses}

For each gene separately, OTU diversity metrics (Chao1 richness estimator, Coleman richness, Shannon Index, and Simpson's Index) were computed using EstimateS (Colwell 2009). Rarefaction curves were created by using Coleman richness estimates from EstimateS. One-way analysis of variance (ANOVA) tests were carried out in JMP (version 5.1.2, SAS Institute) to test for differences in mean Chao1 richness, Coleman richness, Shannon Index, and Simpson's Index among sampling sites and months. Tukey-Kramer post-hoc comparison tests were used to determine which samples drove the overall differences in richness by month. For ANOVA tests, we used richness and diversity values rarefied to the lowest common sample size $(n=12)$, and samples consisting of fewer than 12 sequences were eliminated from that analysis. To test for differences in OTU composition among sampling sites and months, we performed analysis of similarities (ANOSIM, 2-way with no replication) using Primer 6 (PRIMER-E). Prior to the ANOSIM tests, samples consisting of fewer than 14 sequences were removed, and similarity matrices were calculated from OTU relative abundance using a non-weighted Bray-Curtis similarity metric.

\section{RESULTS}

\section{g20 sequence diversity}

Over $95 \%$ of the cyanophage isolates yielded positive amplicons with myovirus-specific g20 PCR primers, suggesting that nearly all of the isolates are cyanomyoviruses. In total, high quality g20 sequences were obtained from 916 cyanophage isolates, which grouped into 16 OTUs at a $99 \%$ sequence similarity threshold. These $g 20$ OTUs, or taxa, are hereafter designated as S-CAMs (Synechococcus-infecting California myovirus). A majority $(621 ; 61 \%)$ of the $g 20$ sequences grouped into a single OTU, SCAM1, while 8 of the OTUs comprised only a single sequence (Fig. 1, Table 1). Although our culturebased method can only capture a limited amount of cyanophage diversity (Table 1), a rarefaction curve indicates that we probably observed most of the common taxa (identified by the g20 gene) capable of 


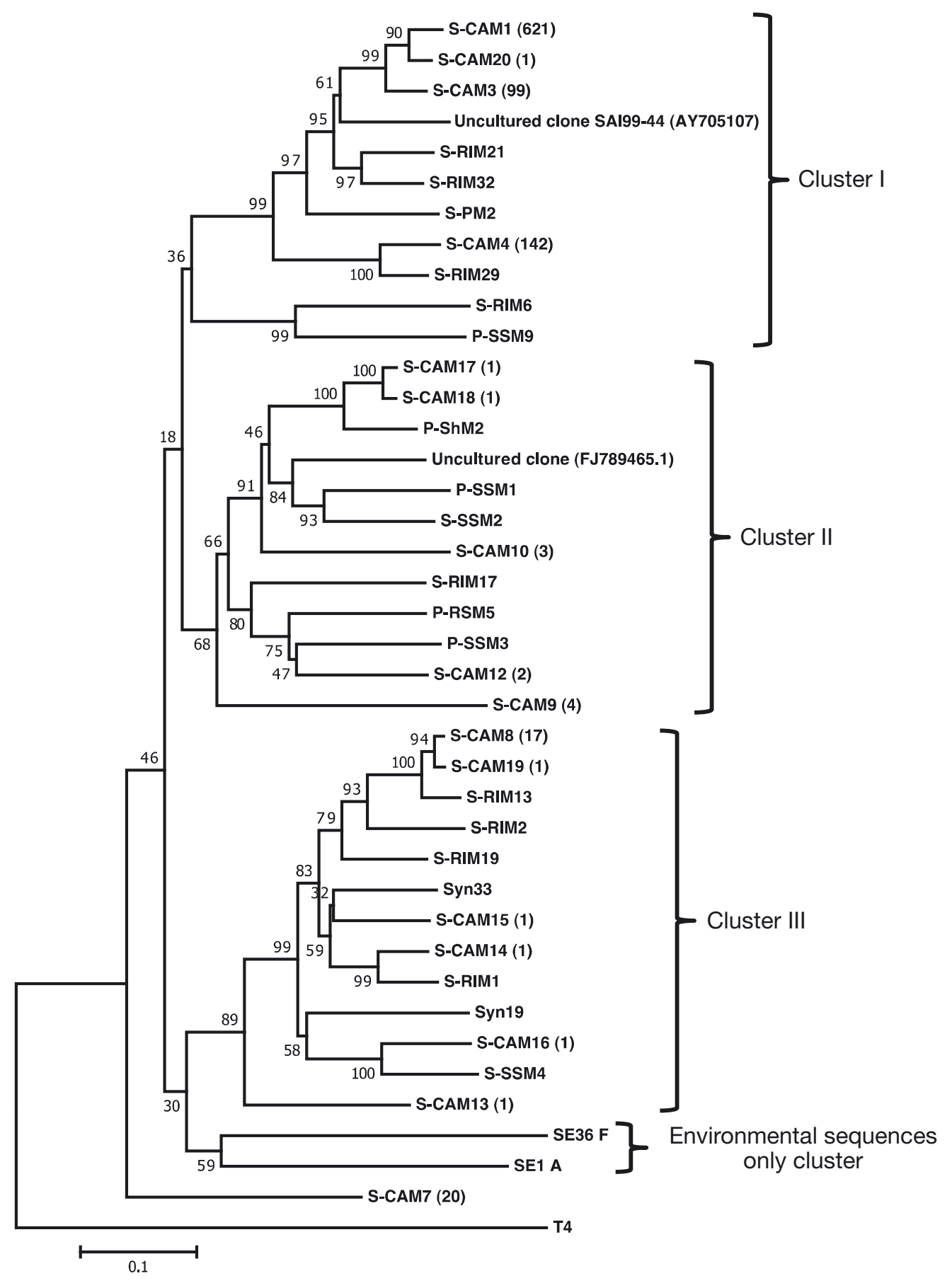

Fig. 1. Phylogenetic relationships of the Southern California cyanomyovirus (S-CAM) operational taxonomic units (OTUs) based on $g 20$ nucleotide sequences and selected other $g 20$ reference sequences. The number of isolates observed from each S-CAM taxon are shown in parentheses. Clusters were assigned according to Sullivan et al. (2008). Bootstrap values are indicated at the nodes

being isolated by our culturing method (Fig. S1 in the Supplement at www.int-res.com/articles/suppl/a069 p017_supp.pdf).

The $g 20$ OTUs were phylogenetically diverse, representing all 3 of the previously defined major phylo- genetic clusters containing cultured representatives (Zhong et al. 2002) (Fig. 1). However, the majority of g20 sequences $(\sim 94 \%)$, including the top 3 most abundant OTUs (S-CAM1, 3, and 4), fell into Cluster I (sensu Zhong et al. 2002, Sullivan et al. 2008). Five 
Table 1. Number of sequences, OTUs (operational taxonomic units), singletons, mean Chao1 estimate (CIs), and the mean $( \pm \mathrm{SD})$ of the Coleman richness, Shannon Index, and Simpson's Index observed for the total sequences and for $g 20$ sequences collected in each month and site. To facilitate comparisons across samples, the reported values for the Coleman richness, Shannon Index, and Simpson's Index in the $g 20$ by month and by site categories are rarefied to the lowest number available within each category (10 for the month category, and 280 for the site category). BI = Balboa Island, CC $=\mathrm{Crystal}$ Cove, $\mathrm{SB}=$ Seal Beach

\begin{tabular}{|c|c|c|c|c|c|c|c|}
\hline & $\begin{array}{c}\text { No. of } \\
\text { sequences }\end{array}$ & $\begin{array}{l}\text { No. of } \\
\text { OTUs }\end{array}$ & $\begin{array}{c}\text { No. of } \\
\text { singletons }\end{array}$ & $\begin{array}{l}\text { Chao1 } \\
\text { richness }\end{array}$ & $\begin{array}{c}\text { Coleman } \\
\text { richness }\end{array}$ & $\begin{array}{l}\text { Shannon } \\
\text { Index }\left(H^{\prime}\right)\end{array}$ & $\begin{array}{l}\text { Simpson's } \\
\text { Index }(D)\end{array}$ \\
\hline g20 total & 915 & 16 & 8 & $48(21,227)$ & 16 & 1.0 & 2.0 \\
\hline$p s b A$ total & 790 & 28 & 20 & $228(63,1170)$ & 28 & 1.2 & 2.1 \\
\hline \multicolumn{8}{|c|}{ g20 by month } \\
\hline Jan-08 & 11 & 3 & 1 & $3(3,3)$ & $2.9 \pm 0.3$ & $0.8 \pm 0.1$ & $2.3 \pm 0.3$ \\
\hline Feb-08 & 19 & 3 & 0 & $3(3,3)$ & $2.7 \pm 0.5$ & $0.7 \pm 0.2$ & $1.9 \pm 0.4$ \\
\hline Mar-08 & 47 & 7 & 4 & $15(8,72)$ & $3.2 \pm 1.0$ & $0.9 \pm 0.3$ & $2.8 \pm 1.0$ \\
\hline Apr-08 & 10 & 1 & 0 & $1(1,1)$ & $1.0 \pm 0.0$ & $0.0 \pm 0.0$ & $1.0 \pm 0.0$ \\
\hline May-08 & 16 & 4 & 2 & $5(4,17)$ & $3.3 \pm 0.7$ & $1.0 \pm 0.2$ & $3.1 \pm 0.5$ \\
\hline Jun-08 & 97 & 5 & 2 & $7(5,27)$ & $2.0 \pm 0.8$ & $0.4 \pm 0.3$ & $1.5 \pm 0.5$ \\
\hline Jul-08 & 66 & 5 & 1 & $5(5,9)$ & $2.5 \pm 0.8$ & $0.6 \pm 0.3$ & $1.8 \pm 0.5$ \\
\hline Aug-08 & 110 & 6 & 1 & $6(6,11)$ & $3.0 \pm 0.8$ & $1.0 \pm 0.2$ & $3.0 \pm 0.8$ \\
\hline Sep-08 & 130 & 6 & 2 & $7(6,17)$ & $1.7 \pm 0.7$ & $0.3 \pm 0.3$ & $1.2 \pm 0.3$ \\
\hline Oct-08 & 112 & 2 & 0 & $2(2,2)$ & $1.2 \pm 0.4$ & $0.1 \pm 0.2$ & $1.0 \pm 0.1$ \\
\hline Nov-08 & 89 & 2 & 1 & $2(2,2)$ & $1.1 \pm 0.3$ & $0.0 \pm 0.1$ & $1.0 \pm 0.1$ \\
\hline Dec-08 & 107 & 1 & 0 & $1(1,1)$ & $1.0 \pm 0.0$ & $0.0 \pm 0.0$ & $1.0 \pm 0.0$ \\
\hline Jan-09 & 36 & 2 & 0 & $2(2,2)$ & $1.7 \pm 0.5$ & $0.3 \pm 0.2$ & $1.3 \pm 0.3$ \\
\hline Feb-09 & 53 & 1 & 0 & $1(1,1)$ & $1.0 \pm 0.0$ & $0.0 \pm 0.0$ & $1.0 \pm 0.0$ \\
\hline Mar-09 & 12 & 1 & 0 & $1(1,1)$ & $1.0 \pm 0.0$ & $0.0 \pm 0.0$ & $1.0 \pm 0.0$ \\
\hline \multicolumn{8}{|l|}{ g20 by site } \\
\hline $\mathrm{BI}$ & 280 & 11 & 5 & $24(13,105)$ & $11.0 \pm 0.0$ & $1.1 \pm 0.0$ & $2.1 \pm 0.0$ \\
\hline $\mathrm{CC}$ & 354 & 8 & 3 & $11(8,33)$ & $7.4 \pm 0.7$ & $0.9 \pm 0.0$ & $1.8 \pm 0.1$ \\
\hline SB & 281 & 9 & 3 & $12(9,34)$ & $9.0 \pm 0.1$ & $1.1 \pm 0.0$ & $2.2 \pm 0.0$ \\
\hline
\end{tabular}

additional OTUs (11 sequences total) fell within Cluster II, while another 6 OTUs (22 sequences total) associated with Cluster III. S-CAM7, represented by 20 sequences, fell onto a long branch with low bootstrap support that did not clearly group within any of the previously defined major clusters. As expected, none of the sequences fell within the A to F environmental sequence-only clusters, which to date contain no known cultured representatives (Zhong et al. 2002, Sullivan et al. 2008).

Although the S-CAMs were closely related to previously observed cyanomyoviruses (Fig. 1), many taxa appeared to be novel. The $g 20$ sequences of S-CAM strains ranged from 72.3 to $96.5 \%$ in nucleotide identity (blastn) with sequences deposited in GenBank (Table S1 in the Supplement); 74 to $100 \%$ in amino acid identity (blastx) with sequences deposited in GenBank (Table S2 in the Supplement); and up to $96 \%$ in nucleotide identity with sequences in the GOS metagenomic dataset (MEGA BLAST). The most abundant taxon, S-CAM1, was just $87 \%$ identical in nucleotide sequence and $98 \%$ identical in amino acid sequence to the top GenBank BLAST hit, cyanophage clone SAI99-44 deposited by Short \&
Suttle (2005), and $96 \%$ identical to a GOS sequence from the coast of South Carolina. Further, only 1 OTU, S-CAM4, was $100 \%$ identical in amino acids to a previously observed sequence - that of S-RIM29, isolated from Mt. Hope Bay, Rhode Island (Marston \& Sallee 2003). However, at the nucleotide level, SCAM4 was only $91 \%$ identical to S-RIM29 (44 nucleotide differences). S-CAM14, a rare OTU in our samples, was also highly similar in amino acid sequence to a deposited sequence, differing by a single amino acid from 'Synechococcus phage 44A' isolated by Zhong et al. (2002). Conversely, S-CAM7 was the most dissimilar from sequences in the databases, sharing only 72 and $74 \%$ in nucleotide and amino acid identity to the top hits, respectively.

\section{$\operatorname{psbA}$ sequence diversity}

We successfully amplified psbA from $95 \%$ of the cyanophage isolates using primers developed by Wang \& Chen (2008). High quality psbA sequences were obtained from 790 isolates, which formed 28 OTUs at a $99 \%$ sequence similarity threshold. While 


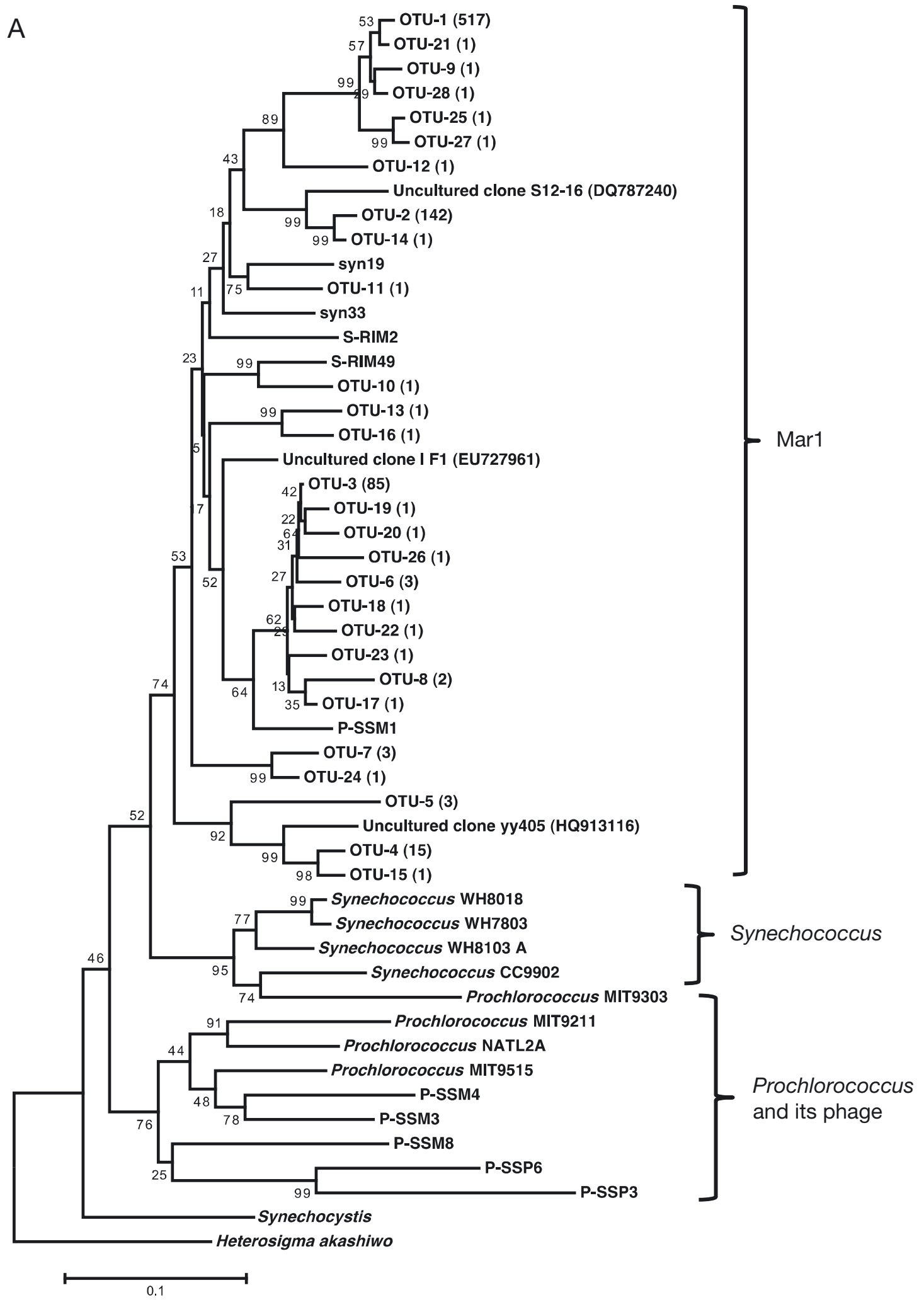

Fig. 2. (Above and following page.) Phylogenetic relationships of the Southern California cyanophage psbA operational taxonomic units (OTUs) based on (A) nucleotide and (B) amino acid sequences. In (A) the number of isolates observed from each OTU are shown in parentheses. Phylogenetic 'Mar1' group refers to the marine cyanobacteria-infecting myovirus clade according to Chénard \& Suttle (2008). Bootstrap values are indicated at the nodes 


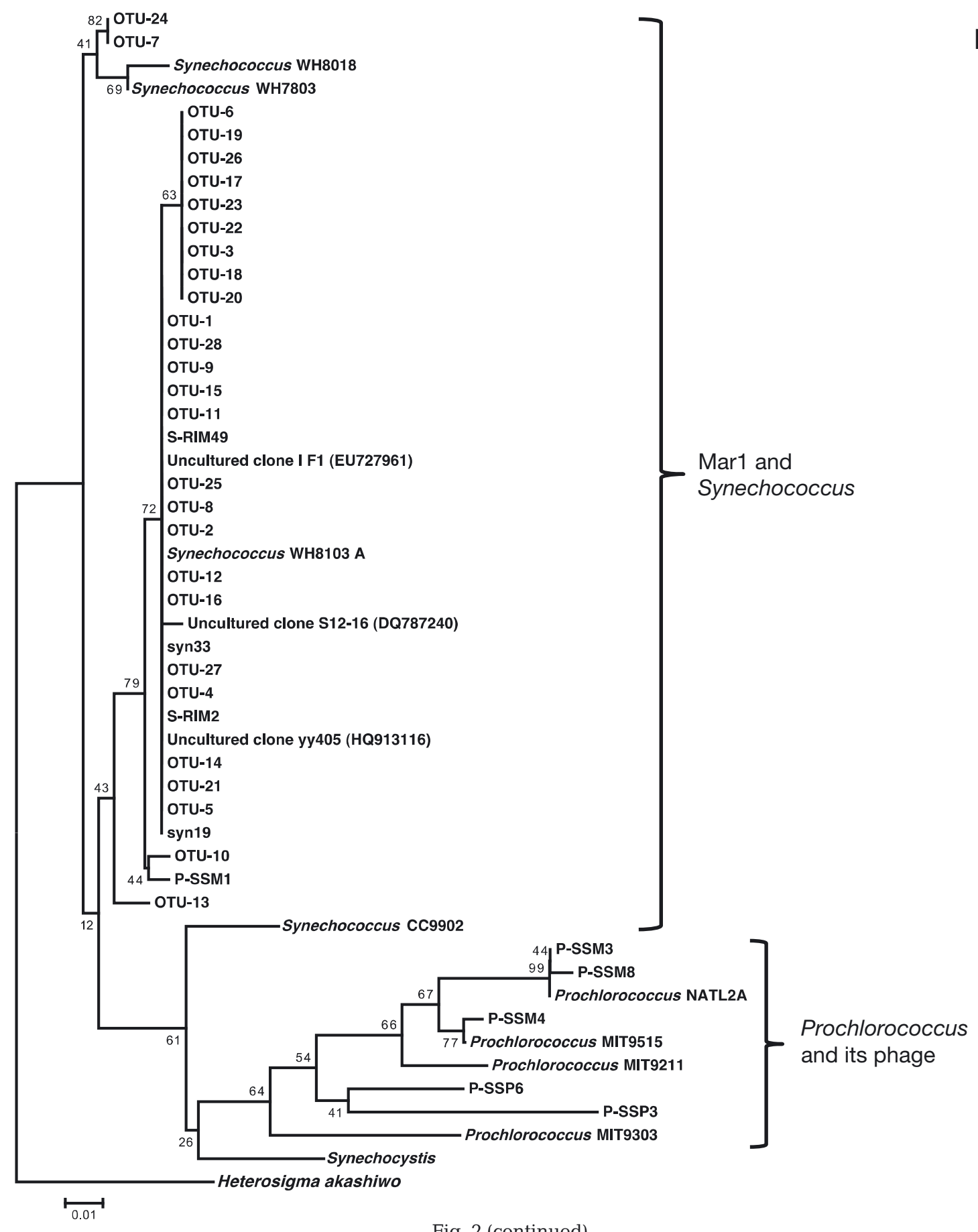

Fig. 2 (continued)

517 of these sequences fell into a single OTU (OTU1), 20 of the OTUs were composed of only 1 sequence (Table 1, Fig. 2). Notably, psbA could not be amplified from any of the 14 cyanophages isolated in April 2008 or from $33 \%$ of the cyanophages isolated in May 2008. In the majority of cases, these $p s b A$-negative isolates from April and May belonged to S-
CAM7 by analysis of the $g 20$ gene; otherwise, they were either non-amplifiable for $g 20(11 \%)$, or did not produce a good quality $g 20$ sequence $(3 \%)$.

The $p s b A$ OTUs were well distributed across a single phylogenetic cluster, the Mar1 group (as previously described by Chénard \& Suttle 2008), (Fig. 2A). However, none of the psbA OTUs were identical in 
nucleotide sequence to those previously deposited in GenBank (Table S3 in the Supplement) or in the GOS metagenomic dataset. The $p s b A$ OTUs ranged from 85.4 to $94.8 \%$ in nucleotide identity (blastn) with sequences in GenBank and up to $94 \%$ in nucleotide identity with sequences in GOS. The highest match was between the rare OTU-7, and the cultured phage S-RSM2 at $94.8 \%$ similarity. The most abundant OTU (OTU-1) had a psbA sequence that was only $87 \%$ identical in nucleotide sequence to 'uncultured cyanophage clone FRP962' sampled from the waters of the Northeastern Pacific by Chénard \& Suttle (2008), 86.8\% identical to cultured cyanophage Syn19, and $85 \%$ identical to a GOS sequence from the Gulf of Maine.

Despite low identity at the nucleotide level, all of the psbA OTUs were $100 \%$ similar in psbA amino acid sequence (blastx) with other cultured and environmental sequences deposited in GenBank. Moreover, there was very little amino acid variation among our psbA OTUs, as the majority of isolates were 99.95 to $100 \%$ similar to each other in psbA amino acid sequence (Fig. 2B). Most of the psbA OTUs fell into 2 clades, which differed by a single amino acid. While we did observe slight variation in the ${ }^{\mathrm{R}} /{ }_{\mathrm{K}} \mathrm{ETTXXXS}{ }^{\mathrm{Q}} / \mathrm{H}$ variable triplet motif identified by Sharon et al. (2007) among our psbA OTUs, variation at this site did not account for the divergence of the 2 major clusters. Instead a region $\sim 80$ residues upstream contained the amino acid substitution responsible for the 1 amino acid difference between the 2 main clades. Only 4 rare OTUs grouped outside of these 2 clades, with the largest amino acid divergence between any pair being 6 amino acids, or $3 \%$ (e.g. OTU-7 compared to OTU-3). In only a few of these cases did variation in the ${ }_{\mathrm{K}} \mathrm{ETTXXXS}^{\mathrm{Q}} / \mathrm{H}$ motif explain the amino acid divergence (OTU-7 and -24 having the sequence ENE, while all other OTUs having ETE at the variable triplet site). These 2 triplet sequences are equivalent to the 2 most abundant motifs that were found in $p s b A$ sequences from the GOS dataset (Sharon et al. 2007), suggesting that our isolation method detected the globally most common psbA types.

\section{Comparison of diversity across the 2 genes}

Overall, the $p s b A$ gene fragment resulted in greater observed taxonomic richness than the $g 20$ gene (28 versus 16 OTUs; Table 1), which is also reflected by the steeper rarefaction curve for $p s b A$ (Fig. S1 in the Supplement). Despite this difference in taxonomic richness elicited by the 2 loci, the most abundant psbA OTUs corresponded well to the most abundant $g 20$ OTUs: S-CAM1 corresponds to $p s b A$ OTU-1; S-CAM4 to $p s b A$ OTU-2; S-CAM3 to $p s b A$ OTU-3; and S-CAM8 to psbA OTU-4, indicating taxonomic congruence of the genes at the nucleotide level. The most notable difference between $p s b A$ and $g 20$ OTUs was the lack of a psbA OTU corresponding to S-CAM7, as the isolates in this OTU were negative for $p s b A$ amplification. Any other discrepancies between $g 20$ and psbA OTUs can be attributed to differing sample sizes (number of quality sequences obtained each month for each gene) or to the greater proportion of rare OTUs for $p s b A$ (i.e. more psbA singletons at the 99\% cutoff), possibly due to high levels of intragenic recombination reported for this gene (Marston \& Amrich 2009).

However, at the amino acid level, the psbA gene was much more conserved than the $g 20$ gene. A phylogenetic tree based on g20 amino acid alignments (Fig. S2 in the Supplement at www.int-res.com/ articles/suppl/a069p017_supp.pdf) exhibited a similar topology to the $g 20$ nucleotide tree and only 1 pair of g20 OTUs were $100 \%$ identical to each other in amino acid sequence (S-CAM8 and S-CAM19). By contrast, the majority of psbA OTUs, including the most common ones, were $100 \%$ identical to each other in amino acid sequence (Fig. 2B).

\section{Temporal and spatial variation in cyanophage isolates}

The abundance of cyanophages infectious to Synechococcus sp. WH7803 (recorded at the BI site only; see 'Materials and methods' for a description) varied over time. Specifically, we observed highest abundances in July and August 2008, and lowest abundances in winter, spring, and late fall months, except for a peak in abundance in February 2008 (Fig. 3A). Average weekly sea surface temperatures recorded at the nearby Newport Pier exhibited a similar trend: warmest temperatures in summer months and coolest in winter months, with an overall range of 13.5 to $21.8^{\circ} \mathrm{C}$ (Fig. 3A).

The taxonomic composition of cyanophage isolates also exhibited striking temporal variation over the 15 mo of sampling, but little spatial variation across the 3 Southern California sites. There were distinct temporal fluctuations in the relative abundances of the most common OTUs, and these fluctuations were highly similar for both genes (Fig. 3B,C). Moreover, overall OTU composition based on both g20 and 

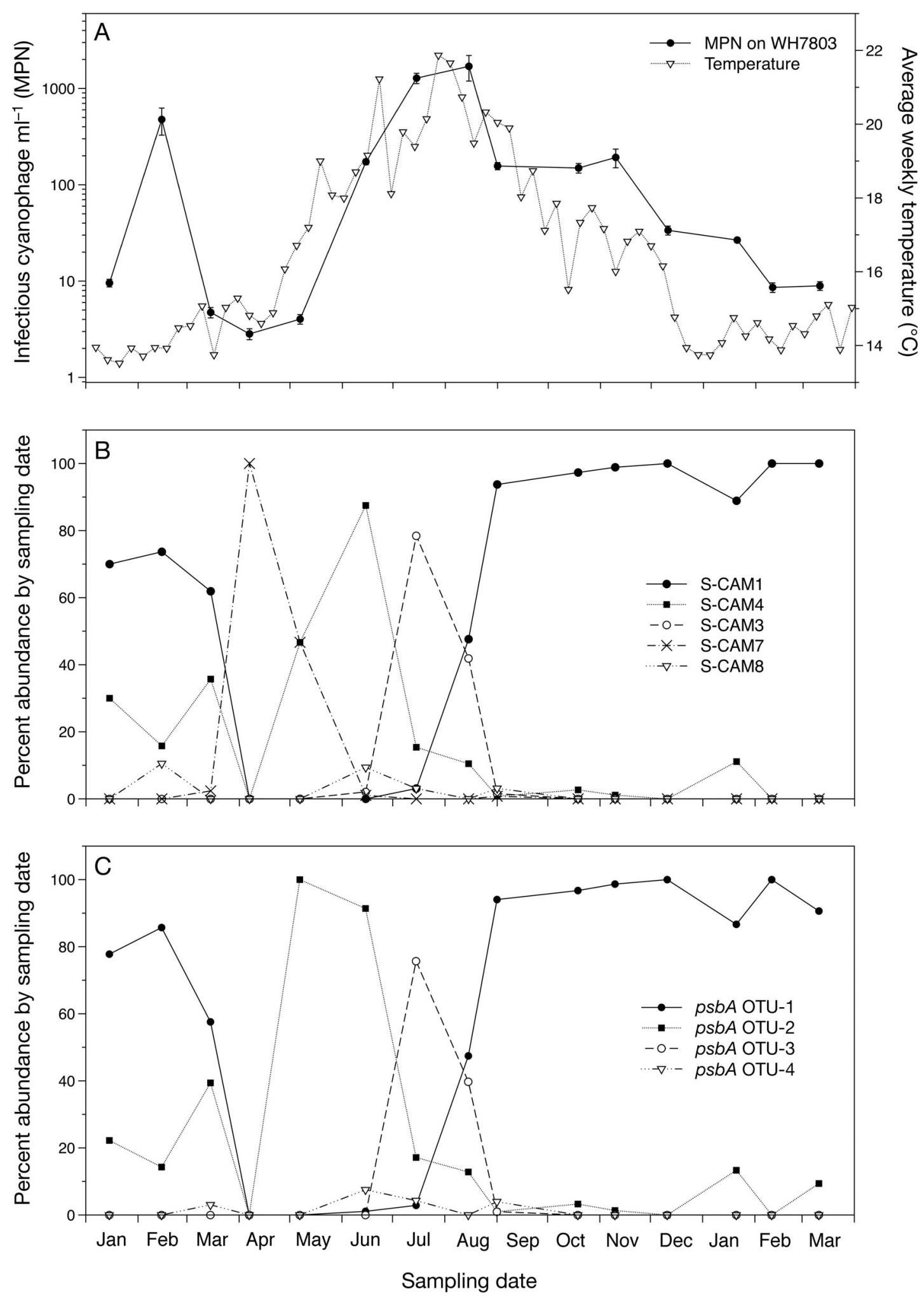

Fig. 3. Temporal dynamics from January 2008 to March 2009 in (A) the abundance of cyanophages infectious to Synechococcus strain WH7803 (at the Balboa Island site) estimated using a most probable number (MPN) assay and average weekly surface seawater temperature (at Newport Beach Pier); and the percent abundance of each of the most common (B) S-CAM OTUs and (C) psbA OTUs. (B,C) Data are presented as percentage of each OTU (out of the 5 or 4 most common OTUs, for S-CAM and $p s b A$ OTUs, respectively) within each monthly sample 
psbA differed significantly among sampling months (ANOSIM: $\rho=0.913, p=0.001$ and $\rho=0.838, p=$ 0.001 , for $g 20$ and $p s b A$, respectively). Composition fluctuated most dramatically over the spring and summer months (March to August 2008), during which the identity of the dominant OTU changed frequently. Conversely, composition was less dynamic during the fall and winter (January to March 2008 and September 2008 to March 2009) when a single OTU, g20 S-CAM1 and psbA OTU-1, dominated the community. During some of these months, $100 \%$ of the isolated cyanophages belonged to this single dominant OTU. In contrast to this variation over time, composition did not vary over space among the 3 sampling sites (ANOSIM: $\rho=0.1, p=0.24$ and $\rho=$ $-0.095, \mathrm{p}=0.76$, respectively, for $g 20$ and $p s b A$ ).

Like the patterns observed for taxonomic composition, richness and diversity of the cyanophage isolates also varied more dramatically over time than space. g20 OTU richness and diversity measures (Coleman, Shannon and Simpson) differed by sampling month (ANOVA: $p<0.0001$ for all metrics, except Chao1: $\mathrm{p}=0.099$; e.g. Coleman richness $F=$ 9.47, $\mathrm{df}=8, \mathrm{p}<0.0001)$. The spring and summer months generally harbored a more diverse cyanophage community than the late fall and winter months (Tukey-Kramer Honestly Significant Difference post-hoc comparisons; Table 1, Fig. 3B,C). Although the Balboa Island site tended to have higher richness and diversity values (Table 1), this trend was not significant for any of the 4 metrics (e.g. Coleman richness $F=0.59, \mathrm{df}=2, \mathrm{p}=0.5$ ).

\section{DISCUSSION}

Cyanophage communities infecting Synechococcus sp. WH7803 exhibited striking temporal variation over a 15 mo time period, but did not vary spatially among 3 coastal sites in Southern California. The lack of spatial differentiation is not surprising given that ocean currents and tidal flux are likely responsible for maintaining well-mixed communities along this coastal region at a relatively small scale (maximum distance apart is approximately $32 \mathrm{~km}$ ). Similarly, within the Chesapeake Bay, at distances up to $300 \mathrm{~km}$ apart, cyanophage communities were much more variable over time than over space (Wang \& Chen 2004).

The temporal variation in cyanophage abundance observed here (Fig. 3A) is similar to that of other studies in a variety of marine locations. In particular, the abundances of total viruses and cyanophages tend to be greatest in warmer seasons and/or lowest in the winter (Waterbury \& Valois 1993, Jiang \& Paul 1994, Suttle \& Chan 1994, Cochran \& Paul 1998, Marston \& Sallee 2003, Millard \& Mann 2006, Sandaa \& Larsen 2006, Wang et al. 2011, Parsons et al. 2012). Some of these studies also found that cyanophage abundances co-vary with cyanobacterial abundance and temperature (e.g. Waterbury \& Valois 1993, Sandaa \& Larsen 2006, Wang et al. 2011), resembling the trend we observed here in Southern California (Fig. 3A).

We also identified changes in cyanophage composition and diversity over time. In particular, the fall and winter community, dominated by a single taxon, was distinct from the more diverse spring and summer community. Similar temporal variation in coastal cyanophage composition has also been observed on the Atlantic coast of the United States within the Chesapeake Bay (Wang \& Chen 2004) and in Rhode Island coastal waters (Marston \& Sallee 2003, Marston et al. 2012), in the coastal waters of Norway (Sandaa \& Larsen 2006), and in the Red Sea (Mühling et al. 2005). These studies also reported a temporal pattern in cyanophage diversity, often with lower richness in winter months than summer months. Taken together, these results suggest that seasonal variation in composition and diversity is a common pattern in coastal cyanophage communities.

Chow \& Fuhrman (2012) recently documented strong seasonal variation in the composition of the total community of uncultured myoviruses (including myoviruses that infect non-cyanobacteria) in the San Pedro Channel off the coast of Southern California, near our sampling sites. Their findings are consistent with ours in that the fall and winter community was distinct from the spring and summer community, substantiating our result based on a more limited subset of viral diversity (culturable cyanomyoviruses infective to Synechococcus sp. WH7803). As expected, Chow \& Fuhrman (2012) detected an overall more diverse myovirus community across all seasons than detected by our method. However, we speculate that the cyanophage diversity targeted in our study represents an ecologically similar group of viruses since they likely infect a similar subset of all cyanobacteria. For instance, the dominance of a single cyanophage taxon in winter months observed in our study may indicate a corresponding dominance of a particular Synechococcus phenotype as measured by its susceptibility to phage infection. Indeed, Tai \& Palenik (2009) demonstrated a seasonal pattern in the distribution of several Synechococcus phylogenetic clades in Southern California coastal water. 
Although our isolation method certainly limits the amount of cyanophage diversity that is detected, it has 2 main advantages. First, we are capable of targeting only viable infectious phage from the large fraction in the ocean that are likely not infective (Suttle \& Chen 1992, Wommack et al. 1996) and second, the genome and physiology of the host strain is wellknown. Thus, our isolation-based approach may provide a useful indicator of ecologically relevant phage diversity and potential phage-host interactions that are not possible with culture-independent methods. Nonetheless, work is underway to confirm our findings based on cultured isolates with data from culture-independent direct sequencing at our sites. We expect the directly sequenced samples to consist of a significant proportion of the diversity detected using the isolation-based approach, as has been recently reported using similar methods for samples collected in Atlantic coastal waters (Marston et al. 2012).

Interestingly, the majority of our cyanophage OTUs were at least $10 \%$ divergent in nucleotide and amino acid sequences from both uncultured and cultured cyanophage sequences present in GenBank (Tables S1-S3 in the Supplement). For example, the most abundant taxon identified in our samples, SCAM1 (61\% of the isolates), was not identical in either $g 20$ or $p s b A$ nucleotide sequence to anything in the databases to date. Although many of the top sequence matches were to other cultured cyanophages isolated on the same Synechococcus host from waters on the Atlantic coast (e.g. Marston \& Sallee 2003), none of the matches were greater than $97 \%$ similar in nucleotide sequence to another cultured isolate (Tables S1 \& S3 in the Supplement), suggesting that at least some of our isolates represent novel cultured representatives. Additionally, SCAM7, dominant for a short time during the spring, was highly divergent in sequence similarity from others in the databases and was unable to yield positive psbA amplification. Recent work suggests that psbA is a core gene common to all T4-like cyanomyoviruses (Sullivan et al. 2006, 2010); therefore, it is unclear whether this taxon truly lacks the gene or whether it harbors a divergent psbA sequence not amplified by our primers. Nonetheless, the detection of this divergent genotype suggests the existence of at least some previously undescribed cyanophage diversity in coastal Southern California.

We also found that the temporal patterns in cyanophage communities were consistent for 2 separate genetic loci, commonly used in cyanophage diversity studies: $g 20$, the myovirus-specific portal protein gene; and $p s b A$, a host-derived gene recently discov- ered to be expressed during infection (Lindell et al. 2005, Clokie et al. 2006), and thought to provide a reproductive advantage to phage by boosting host metabolism. In a recent comparative genomic study, Ignacio-Espinoza \& Sullivan (2012) found that most cyanophage core genes (including 920 ) are vertically transferred, while a few (including psbA) exhibit evidence of recombination via lateral transmission. Thus, despite the fact that $p s b A$ and g20 may have different evolutionary origins and histories, we found that taxonomic designations at $99 \%$ nucleotide similarity were highly congruent for both genes. This result agrees with other findings that cyanophage strain genotypes remain stable across multiple loci, including $g 20$ and psbA (Marston \& Amrich 2009), and that recombination within these cyanophage 'core' genes across genetically different strains (or OTUs) appears rare (Marston \& Amrich 2009, Ignacio-Espinoza \& Sullivan 2012). Thus, it appears that either locus can serve as a useful and comparable marker of cyanophage taxonomic composition.

While the psbA sequences of our cyanophage isolates were for the most part taxonomically congruent to $g 20$ at the nucleotide level, the corresponding amino acid sequences were not. These findings are in agreement with other studies suggesting that amino acid conservation at the $p s b A$ locus is due to high purifying selection within both cyanobacterial host genomes and cyanophage genomes (Lindell et al. 2004, Zeidner et al. 2005, Sullivan et al. 2006, Sharon et al. 2007, Marston \& Amrich 2009), despite greater overall rates of molecular evolution for cyanophages (Zeidner et al. 2005). This pattern indicates the importance of carrying a functional $p s b A$ gene for cyanophage fitness in natural environments. Indeed, the protein is highly conserved across all photosynthetic domains (at least 80\% amino acid similarity between cyanobacteria and chloroplasts) (Janssen et al. 1989). This is thought to be due to high selection to maintain the specificity of the D1 protein's multiple binding sites, which are associated with its role as both a transmembrane protein and an electron acceptor (Wu et al. 1987, Janssen et al. 1989). While nucleotide variation in cyanophage $p s b A$ may be a useful indicator of diversity, this variation consists of primarily synonymous mutations due to the conserved function of the protein in the host. Since our isolates are likely all capable of infecting a similar subset of Synechococcus cells, then purifying selection to maintain functioning of a similar D1 protein within these hosts might explain the lack of $p s b A$ amino acid divergence among our isolates. 
The temporal dynamics of cyanophage abundance and composition observed in this study corresponds well with the growing body of recent studies demonstrating that marine microbes are generally highly dynamic over time and often seasonally patterned (reviewed by Giovannoni \& Vergin 2012). More work is needed to understand what factors may be driving this temporal variation in marine microbial communities, whether it is seasonally predictable (as in Fuhrman et al. 2006, Gilbert et al. 2012) in all areas of the world's oceans, and which microbial taxa tend to drive the patterns. One of the major outcomes of such work thus far is an increasing appreciation of how crucial the timing of sampling is for comparative marine microbial diversity studies (Giovannoni \& Vergin 2012). For instance, the timing of sampling may explain much of the variation in bacterial diversity observed across studies, as changes in the relative abundance (not presence-absence) are responsible for variation in bacterial composition over time (Caporaso et al. 2012). As a result, previous studies characterizing phage diversity at multiple locations at single points in time (e.g. Zhong et al. 2002, Sullivan et al. 2008, Jameson et al. 2011) may miss ecologically relevant patterns. Thus, further studies that simultaneously investigate both temporal and spatial patterns are needed to elucidate the factors that influence the abundance and diversity of marine phages, and ultimately, their impact on their bacterial hosts.

Acknowledgements. We thank members of the J. Martiny laboratory for assistance with environmental sampling, host culture maintenance, and cyanophage isolation. Funding for this research was provided by the Gordon and Betty Moore Foundation, the National Science Foundation (OCE1005388 and OCE-1031783), and a NOAA NERRS Graduate Research Fellowship (Estuarine Reserves Division, Office of Ocean and Coastal Resource Management, National Oceanic and Atmospheric Administration) to C.A.H.

\section{LITERATURE CITED}

Angly FE, Felts B, Breitbart M, Salamon P and others (2006) The marine viromes of four oceanic regions. PLoS Biol 4: e368

Breitbart M, Rohwer F (2005) Here a virus, there a virus, everywhere the same virus? Trends Microbiol 13: 278-284

Breitbart M, Salamon P, Andresen B, Mahaffy JM and others (2002) Genomic analysis of uncultured marine viral communities. Proc Natl Acad Sci USA 99:14250-14255

Breitbart M, Miyake JH, Rohwer F (2004) Global distribution of nearly identical phage-encoded DNA sequences. FEMS Microbiol Lett 236:249-256
Caporaso JG, Paszkiewicz K, Field D, Knight R, Gilbert JA (2012) The Western English Channel contains a persistent microbial seed bank. ISME J 6:1089-1093

> Chen F, Wang K, Huang SJ, Cai HY, Zhao ML, Jiao NZ, Wommack KE (2009) Diverse and dynamic populations of cyanobacterial podoviruses in the Chesapeake Bay unveiled through DNA polymerase gene sequences. Environ Microbiol 11:2884-2892

> Chénard C, Suttle CA (2008) Phylogenetic diversity of sequences of cyanophage photosynthetic gene $p s b A$ in marine and freshwaters. Appl Environ Microbiol 74: 5317-5324

Chow CE, Fuhrman JA (2012) Seasonality and monthly dynamics of marine myovirus communities. Environ Microbiol 14:2171-2183

Clokie MR, Shan J, Bailey S, Jia Y, Krisch HM, West S, Mann NH (2006) Transcription of a 'photosynthetic' T4type phage during infection of a marine cyanobacterium. Environ Microbiol 8:827-835

Cochran PK, Paul JH (1998) Seasonal abundance of lysogenic bacteria in a subtropical estuary. Appl Environ Microbiol 64:2308-2312

Colwell RK (2009) EstimateS: statistical estimation of species richness and shared species from samples. Available at http://purl.oclc.org/estimates

Culley AI, Lang AS, Suttle CA (2006) Metagenomic analysis of coastal RNA virus communities. Science 312: 1795-1798

Dorigo U, Jacquet S, Humbert JF (2004) Cyanophage diversity, inferred from $g 20$ gene analyses, in the largest natural lake in France, Lake Bourget. Appl Environ Microbiol 70:1017-1022

Felsentein J (1993) PHYLIP (Phylogeny Inference Package). Department of Genetics, University of Washington, Seattle, WA

Frederickson CM, Short SM, Suttle CA (2003) The physical environment affects cyanophage communities in British Columbia inlets. Microb Ecol 46:348-357

Fuhrman JA (1999) Marine viruses and their biogeochemical and ecological effects. Nature 399:541-548

Fuhrman JA, Hewson I, Schwalbach MS, Steele JA, Brown MV, Naeem S (2006) Annually reoccurring bacterial communities are predictable from ocean conditions. Proc Natl Acad Sci USA 103:13104-13109

> Fuller NJ, Wilson WH, Joint IR, Mann NH (1998) Occurrence of a sequence in marine cyanophages similar to that of T4 $\mathrm{g} 20$ and its application to PCR-based detection and quantification techniques. Appl Environ Microbiol 64:2051-2060

> Garza DR, Suttle CA (1998) The effect of cyanophages on the mortality of Synechococcus spp. and selection for UV resistant viral communities. Microb Ecol 36: 281-292

Gilbert JA, Steele JA, Caporaso JG, Steinbrueck L and others (2012) Defining seasonal marine microbial community dynamics. ISME J 6:298-308

Giovannoni SJ, Vergin KL (2012) Seasonality in ocean microbial communities. Science 335:671-676

Huang S, Wilhelm SW, Jiao N, Chen F (2010) Ubiquitous cyanobacterial podoviruses in the global oceans unveiled through DNA polymerase gene sequences. ISME J 4:1243-1251

> Ignacio-Espinoza JC, Sullivan MB (2012) Phylogenomics of T4 cyanophages: lateral gene transfer in the 'core' and origins of host genes. Environ Microbiol. 14:2113-2126 
Jameson E, Mann NH, Joint I, Sambles C, Muhling M (2011) The diversity of cyanomyovirus populations along a North-South Atlantic Ocean transect. ISME J 5: 1713-1721

> Janssen I, Jakowitsch J, Michalowski CB, Bohnert HJ, Loffelhardt W (1989) Evolutionary relationship of psbA genes from cyanobacteria, cyanelles and plastids. Curr Genet 15:335-340

> Jiang SC, Paul JH (1994) Seasonal and diel abundance of viruses and occurrence of lysogeny/bacteriocinogeny in the marine environment. Mar Ecol Prog Ser 104:163-172

Lindell D, Sullivan MB, Johnson ZI, Tolonen AC, Rohwer F, Chisholm SW (2004) Transfer of photosynthesis genes to and from Prochlorococcus viruses. Proc Natl Acad Sci USA 101:11013-11018

Lindell D, Jaffe JD, Johnson ZI, Church GM, Chisholm SW (2005) Photosynthesis genes in marine viruses yield proteins during host infection. Nature 438:86-89

Mann NH (2003) Phages of the marine cyanobacterial picophytoplankton. FEMS Microbiol Rev 27:17-34

Marston MF, Amrich CG (2009) Recombination and microdiversity in coastal marine cyanophages. Environ Microbiol 11:2893-2903

Marston MF, Sallee JL (2003) Genetic diversity and temporal variation in the cyanophage community infecting marine Synechococcus species in Rhode Island's coastal waters. Appl Environ Microbiol 69:4639-4647

> Marston MF, Taylor S, Sme N, Parsons RJ, Noyes TJE, Martiny JBH (2012) Marine cyanophages exhibit local and regional biogeography. Environ Microbiol (in press)

Middelboe M, Hagström Å, Blackburn N, Sinn B and others (2001) Effects of bacteriophages on the population dynamics of four strains of pelagic marine bacteria. Microb Ecol 42:395-406

Millard AD, Mann NH (2006) A temporal and spatial investigation of cyanophage abundance in the Gulf of Aqaba, Red Sea. J Mar Biol Assoc UK 86:507-515

Mühling M, Fuller NJ, Millard A, Somerfield PJ and others (2005) Genetic diversity of marine Synechococcus and cooccurring cyanophage communities: evidence for viral control of phytoplankton. Environ Microbiol 7:499-508

Parsons RJ, Breitbart M, Lomas MW, Carlson CA (2012) Ocean time-series reveals recurring seasonal patterns of virioplankton dynamics in the northwestern Sargasso Sea. ISME J 6:273-284

Partensky F, Blanchot J, Vaulot D (1999) Differential distribution and ecology of Prochlorococcus and Synechococcus in oceanic waters: a review. Bull Inst Oceanogr (Monaco) 19:457-475

Proctor LM, Fuhrman JA (1990) Viral mortality of marine bacteria and cyanobacteria. Nature 343:60-62

Sandaa RA, Larsen A (2006) Seasonal variations in virushost populations in Norwegian coastal waters: focusing on the cyanophage community infecting marine Synechococcus spp. Appl Environ Microbiol 72:4610-4618

Schloss PD, Westcott SL, Ryabin T, Hall JR and others (2009) Introducing mothur: open-source, platform-independent, community-supported software for describing and comparing microbial communities. Appl Environ Microbiol 75:7537-7541

> Schwalbach MS, Hewson I, Fuhrman JA (2004) Viral effects on bacterial community composition in marine plankton microcosms. Aquat Microb Ecol 34:117-127

Sharon I, Tzahor S, Williamson S, Shmoish M and others (2007) Viral photosynthetic reaction center genes and transcripts in the marine environment. ISME J 1:492-501

Short CM, Suttle CA (2005) Nearly identical bacteriophage structural gene sequences are widely distributed in both marine and freshwater environments. Appl Environ Microbiol 71:480-486

Sullivan MB, Lindell D, Lee JA, Thompson LR, Bielawski JP, Chisholm SW (2006) Prevalence and evolution of core photosystem II genes in marine cyanobacterial viruses and their hosts. PLoS Biol 4:e234

Sullivan MB, Coleman ML, Quinlivan V, Rosenkrantz JE and others (2008) Portal protein diversity and phage ecology. Environ Microbiol 10:2810-2823

Sullivan MB, Huang KH, Ignacio-Espinoza JC, Berlin AM and others (2010) Genomic analysis of oceanic cyanobacterial myoviruses compared with T4-like myoviruses from diverse hosts and environments. Environ Microbiol 12:3035-3056

Sun S, Chen J, Li W, Altintas I and others (2011) Community cyberinfrastructure for Advanced Microbial Ecology Research and Analysis: the CAMERA resource. Nucleic Acids Res 39:D546-D551

> Suttle CA (2007) Marine viruses - major players in the global ecosystem. Nat Rev Microbiol 5:801-812

Suttle CA, Chan AM (1994) Dynamics and distribution of cyanophages and their effect on marine Synechococcus spp. Appl Environ Microbiol 60:3167-3174

> Suttle CA, Chen F (1992) Mechanisms and rates of decay of marine viruses in seawater. Appl Environ Microbiol 58: 3721-3729

Suttle CA, Chan AM, Cottrell MT (1990) Infections of phytoplankton by viruses and reduction of primary production. Nature 347:467-469

> Tai V, Palenik B (2009) Temporal variation of Synechococcus clades at a coastal Pacific Ocean monitoring site. ISME J 3:903-915

Tamura K, Dudley J, Nei M, Kumar S (2007) MEGA4: Molecular Evolutionary Genetics Analysis (MEGA) software version 4.0. Mol Biol Evol 24:1596-1599

Thingstad TF (1997) A theoretical approach to structuring mechanisms in the pelagic food web. Hydrobiologia 363: 59-72

> Thingstad TF (2000) Elements of a theory for the mechanisms controlling abundance, diversity, and biogeochemical role of lytic bacterial viruses in aquatic systems. Limnol Oceanogr 45:1320-1328

Wang GH, Murase J, Asakawa S, Kimura M (2010) Unique viral capsid assembly protein gene $(g 20)$ of cyanophages in the floodwater of a Japanese paddy field. Biol Fertil Soils 46:93-102

> Wang K, Chen F (2004) Genetic diversity and population dynamics of cyanophage communities in the Chesapeake Bay. Aquat Microb Ecol 34:105-116

> Wang K, Chen F (2008) Prevalence of highly host-specific cyanophages in the estuarine environment. Environ Microbiol 10:300-312

> Wang K, Wommack KE, Chen F (2011) Abundance and distribution of Synechococcus spp. and cyanophages in the Chesapeake Bay. Appl Environ Microbiol 77:7459-7468

- Waterbury JB, Valois FW (1993) Resistance to co-occurring phages enables marine Synechococcus communities to coexist with cyanophages abundant in seawater. Appl Environ Microbiol 59:3393-3399

> Waterbury JB, Willey JM (1988) Isolation and growth of marine planktonic cyanobacteria. Methods Enzymol 167: 100-105 
Waterbury JB, Watson SW, Valois FW, Franks DG (1986) Biological and ecological characterization of the marine unicellular cyanobacterium Synechococcus. Can Bull Fish Aquat Sci 214:71-120

Weinbauer MG, Rassoulzadegan F (2004) Are viruses driving microbial diversification and diversity? Environ Microbiol 6:1-11

Wilhelm SW, Suttle CA (1999) Viruses and nutrient cycles in the sea. Viruses play critical roles in the structure and function of aquatic food webs. Bioscience 49:781-788

Williamson SJ, Rusch DB, Yooseph S, Halpern AL and others (2008) The Sorcerer II Global Ocean Sampling Expedition: metagenomic characterization of viruses within aquatic microbial samples. PLoS ONE 3:e1456

Wilson WH, Joint IR, Carr NG, Mann NH (1993) Isolation and molecular characterization of five marine cyanophages propagated on Synechococcus sp Strain WH7803. Appl Environ Microbiol 59:3736-3743

Wilson WH, Fuller NJ, Joint IR, Mann NH (2000) Analysis of cyanophage diversity in the marine environment using

Editorial responsibility: Gunnar Bratbak,

Bergen, Norway denaturing gradient gel electrophoresis. In: Bell CR, Brylinsky M, Johnson-Green P (eds) Microbial biosystems: new frontiers. Proc 8th Int Symp Microbial Ecol. Atlantic Canada Society for Microbial Ecology, Halifax, p 565-570

Wommack KE, Hill RT, Muller TA, Colwell RR (1996) Effects of sunlight on bacteriophage viability and structure. Appl Environ Microbiol 62:1336-1341

Wu NH, Cote JC, Wu R (1987) Structure of the chloroplast psbA gene encoding the $\mathrm{Q}_{\mathrm{B}}$ protein from Oryza-sativa L. Dev Genet 8:339-350

Zeidner G, Bielawski JP, Shmoish M, Scanlan DJ, Sabehi G, Béjà O (2005) Potential photosynthesis gene recombination between Prochlorococcus and Synechococcus via viral intermediates. Environ Microbiol 7:1505-1513

Zhong Y, Chen F, Wilhelm SW, Poorvin L, Hodson RE (2002) Phylogenetic diversity of marine cyanophage isolates and natural virus communities as revealed by sequences of viral capsid assembly protein gene g20. Appl Environ Microbiol 68:1576-1584

Submitted: July 27, 2012; Accepted: January 14, 2013 Proofs received from author(s): March 19, 2013 